\title{
Prevalence of HCV Infections and Co-Infection With HBV and HIV and Associated Risk Factors Among Addicts in Drug Treatment Centers, Lorestan Province, Iran
}

\author{
Hossein Norouzian, Mohammadreza Gholami, ${ }^{1}$ Pegah Shakib, 'Gholamreza Goudarzi,", \\ Hamze Ghobadian Diali, ${ }^{2}$ and Azam Rezvani ${ }^{3}$ \\ ${ }^{1}$ Hepatitis Research Center, Lorestan University of Medical Sciences, Khorramabad, IR Iran \\ ${ }^{2}$ Razi Vaccine Serum Research Institute, Virology Department, Karaj, IR Iran \\ ${ }^{3}$ Deputy of Health Services, Lorestan University of Medical Sciences, Khorramabad, IR Iran \\ ${ }^{*}$ Corresponding author: Gholamreza Goudarzi, Hepatitis Research Center, Lorestan University of Medical Sciences, Khorramabad, IR Iran. Tel/Fax: +98-6633120133, E-mail: \\ goudarzi.gh@gmail.com
}

Received 2014 November 15; Revised 2015 March 1; Accepted 2015 March 9.

\begin{abstract}
Background: Hepatitis $\mathrm{C}$ is an infectious disease caused by blood-borne pathogen, hepatitis C virus (HCV).

Objectives: The purpose of this study was to investigate the prevalence of HCV infection and associated risk factors among addicts in drug treatment centers in Lorestan Province, Iran.

Patients and Methods: A cross-sectional sero-behavioral survey was given to drug addicts in the drug treatment centers of Khorramabad, Lorestan Province, Iran during June 2012 - March 2013. Drug addicts were interviewed using a standard questionnaire including demographic, imprisonment history, and HCV-related risk behavior items. Thereafter, the sera drawn from the participants were tested for anti-HCV antibody (Ab), anti-human immunodeficiency virus (HIV) Ab, and hepatitis B surface antigen (HBsAg).

Results: The mean age of the cohorts was 31.7. Up to $60.2 \%$ of drug users had educational levels less than high school, $67.5 \%$ were selfemployed, and $32.5 \%$ were office workers. The mean duration of drug injection was 6.8 years. Statistical analyses indicated that the prevalence of HCV among drug addicts was positively associated with age, past incarceration, drug injection history, the duration of drug use, and tattooing. In addition, 16.23\% of volunteers were HCV-positive. Of those infected with HCV, 1.10\% was co-infected with HBV, $2.95 \%$ were positive for HIV, and $0.36 \%$ of HCV-positive cases were infected with all three viruses.

Conclusions: The high prevalence of HCV infection among this group implies a high rate of transmission and exposure to the risk of serious diseases. It is important that the high prevalence of HCV infection be taken into consideration to control further transmission of this infection.
\end{abstract}

Keywords: Hepatitis C Virus, Prevalence, Risk Factors, Substance Abuse Treatment Centers

\section{Background}

Hepatitis $C$ is a global health problem. The hepatitis $C$ virus (HCV) is mainly transmitted parenterally or in the course of blood contamination during medical procedures.

Worldwide prevalence rates range from 0.01 to $20 \%$, and the world health organization (WHO) estimates that up to $3 \%$ of the world's population (170 million) have been infected with HCV. In developing countries where resources and facilities may be significantly limited, the prevalence of HCV is higher than in the developed world (1).

Worldwide hepatitis $\mathrm{C}$ data show significant prevalence rates in high-risk populations, ranging from 30\% to 50\%, with injecting drug use being the predominant risk factor $(1,2)$. In Iran, opiates are the most commonly abused drug type, and it has been estimated that $2.8 \%$ of adults ages 15 to 64 are opiate abusers (3). Drug addicts are a high-risk group for acquiring one or more parenterally transmitted infection, such as human immunodeficiency virus (HIV), HCV, hepatitis B virus (HBV), and human T-cell leukemia virus type 1 (HTLV-1) (4).

Identified risk factors for HCV infection include intravenous drug use, exposure to infected blood/blood products, intranasal drug use, and tattooing. High-risk populations in Iran are individuals most at risk for hepatitis C, and include those medically underserved, have a history of IV drug injection, and high-risk behaviors (5-7). The main mode of HCV transmission among injecting drug users (IDUs) is by sharing injection equipment, not limited to needle sharing (8).

Several research studies have also reported that HCV is prevalent among prisoners in Iran $(5,9)$.

Prisoners, as a group with high-risk behaviors, are at a major risk of being infected. HCV is usually more prevalent in incarcerated populations than in the surround-

Copyright (C) 2016, Zahedan University of Medical Sciences. This is an open-access article distributed under the terms of the Creative Commons Attribution-NonCommercial 4.0 International License (http://creativecommons.org/licenses/by-nc/4.0/) which permits copy and redistribute the material just in noncommercial usages, provided the original work is properly cited 
ing community (10). It is also predicted that prison-based sharing practices could exacerbate levels of HCV infection, given the current situation of IDUs in Iran (11). The association between HCV infection and a history of being tattooed inside prison has been reported from other countries (12-14). HCV infection control is an important public health concern, as the majority of infections do not resolve, but lead to chronic infection (11).

Therefore, the determination of the distribution and risk factors of HCV infection is important to understand the main methods of HCV transmission, which in turn may assist health organizations to plan better preventative policies. There are limited data on the prevalence and correlates of HIV/HCV/ HVB co-infection among addicts in Lorestan province, Iran.

\section{Objectives}

The purpose of this study was to survey addicts upon detention in Lorestan to measure the prevalence of co-infection and characterize the risk factors associated with HCV.

\section{Patients and Methods}

A cross-sectional study was carried out on 271 volunteers who were selected from among addicts in the drug treatment centers in Khorramabad, Lorestan, Iran to estimate the prevalence of $\mathrm{HCV}$ and $\mathrm{HIV} / \mathrm{HCV}, \mathrm{HCV} / \mathrm{HBV}$, and associated risk factors during June 20012 - March 213. The study included an interview and blood testing. The questionnaire covered demographic characteristics (e.g., age, gender, and marital status) as well as risk factors, including the duration of drug injection, past incarceration, injection drug, tattooing, a history of surgery, a history of blood transfusion, and a history of liver disease. Volunteers could end the interview at any time or refuse to answer any question. After completion of the interview, blood specimens were collected for those who agreed to participate in the blood test. The sera samples were tested for HBsAg, anti-HCV anibody (Ab), and anti-HIV-Ab. $\mathrm{HIV} / \mathrm{HCV}, \mathrm{HCV} / \mathrm{HBV}$ co-infection, and HIV/HCV/HBV triple infections were defined in our study. All the samples were analyzed using ELISA technique to detect HBsAg (Pishtaz Teb Diagnostics, Iran), HIV-Ab (Wantai, China) and HCV-Ab (Diaplus, Italy) in Razi herbal medicines research center, Lorestan University of Medical Sciences, Khorramabad,
Lorestan, Iran. The EIA procedure was applied according to the Diaplus Inc. catalog guidelines.

\subsection{Statistical Analysis}

The software SPSS Version 16.0 for Windows (SPSS Inc. Chicago, IL, USA) was used for analysis. Univariate analysis using chi-square or Fisher's exact tests were done to assess the association between infection status and associated risk factors. Differences were considered significant when $\mathrm{P}<0.05$.

\section{Results}

\subsection{Sociodemographic Characteristics of the Study Participants}

A total of 271 drug addicts (265 males and 6 females) participated in the study. As shown in Table 1, the majority of participants were male. Study participants ranged in age from 19 to $>51$ years. Their mean age was 31.7 years old. Up to $60.2 \%$ of drug users had educational levels less than high school. Furthermore, 67.5\% were self-employed, 32.5\% were office workers, $93.7 \%$ were single, and $6.3 \%$ were married. The mean duration of drug injection was 6.8 years.

\subsection{Prevalence of $H I V, H C V$, and $H B V$ Infections}

In $20.66 \%$ of the tested participants, at least one of the three viral infections was seen (95\% confidence interval (CI)). Forty-four out of 271 volunteers (16.23\%) were positive for HCV-Ab (95\% CI: 40.17, 46.62). Of those infected with HCV, 3 (1.10\%) were co-infected with HBV (95\% CI: $40.17,46.62), 8(2.95 \%)$ were positive for HIV, and 1 (0.36\%) of HCV-positive cases were infected with all three viruses (95\% CI: 40.17, 46.62).

In the current study, $\mathrm{HCV}(16.23 \%)$ is more prevalent than HIV (2.95\%) and HBV (1.10\%) among all addicts. Detailed results on the prevalence of the three infections in both sexes are shown in Table 1.

\subsection{Prevalence of $H I V / H C V, H C V / H B V$, and $H I V / H C V /$ HBV Co-Infection}

The prevalence of $\mathrm{HIV} / \mathrm{HCV}, \mathrm{HCV} / \mathrm{HBV}$, and $\mathrm{HIV} / \mathrm{HCV} / \mathrm{HBV}$ among volunteers was $2.95 \%, 1.10 \%$, and $0.36 \%$, respectively (Tables 1 and 2).

Table 1. The Prevalence of HIV, HCV, Past or Current HBV, and Viral Co-Infections Among Addicts in Drug Treatment Centers, by Sex and Source of Sampling in Khorramabad, Lorestan, Iran

\begin{tabular}{lccccc}
\hline & \multicolumn{2}{c}{ Total } & \multicolumn{2}{c}{ Male } & Female \\
\cline { 2 - 6 } & Number Tested & Positive Cases $^{\mathbf{a}}$ & Number Tested & Positive Cases $^{\mathbf{a}}$ & Number Tested $^{\text {Positive Cases }^{\mathbf{a}}}$ \\
\hline HCV & 271 & $44(16.23)$ & 265 & $43(15.86)$ & 6 \\
HIV/HCV & 271 & $8(2.95)$ & 265 & $8(2.95)$ & 6 \\
HCV/HBV & 271 & $3(1.10)$ & 265 & $3(1.13)$ & 6 \\
HIV/HCV/HBV All & 271 & $1(0.36)$ & 265 & $1(0.36)$ & 6 \\
three viruses & & & & & 0 \\
\hline
\end{tabular}

${ }^{\mathrm{a}}$ Data are presented as No. (\%). 
Norouzian Het al.

Table 2. The Prevalence of HIV, HCV, HBV, and Viral Co-Infections Among Addicts in Drug Treatment Center, Age Groups and Source of Sampling in Khorramabad, Lorestan, Iran ${ }^{\mathrm{a}}$

\begin{tabular}{|c|c|c|c|c|c|c|}
\hline Age Groups & Number Tested & Positive Cases & $\begin{array}{l}\text { HCV Positive } \\
\text { Cases }\end{array}$ & $\begin{array}{c}\text { HIV/HCV Positive } \\
\text { Cases }\end{array}$ & $\begin{array}{c}\text { HCV/HBV } \\
\text { Positive Cases }\end{array}$ & $\begin{array}{l}\text { HIV/HCV/HBV } \\
\text { Positive Cases }\end{array}$ \\
\hline $19-30$ & 132 & $18(6.64)$ & $15(5.53)$ & $2(0.73)$ & 0 & $1(0.36)$ \\
\hline $31-40$ & 108 & $32(11.80)$ & $25(9.22)$ & $6(2.21)$ & $1(0.36)$ & 0 \\
\hline $41-50$ & 19 & $3(1.1)$ & $3(1.1)$ & 0 & 0 & 0 \\
\hline$>51$ & 10 & $3(1.1)$ & $1(0.36)$ & 0 & $2(0.73)$ & 0 \\
\hline Total & & $56(20.66)$ & $44(16.23)$ & $8(2.95)$ & $3(1.1)$ & $1(0.36)$ \\
\hline
\end{tabular}

${ }^{\mathrm{a}}$ Data are presented as No. (\%).

Table 3. Behavioral Characteristics and Their Association With HCV and Co-Infection (HBV/HIV) Seropositivity Among Addicts in Drug Treatment Centers in Khorramabad, Lorestan, Iran ${ }^{\mathrm{a}}$

\begin{tabular}{|c|c|c|}
\hline Variables & Total $(n=271)$ & HCV and Co-Infection (HBV/HIV) Positive $1(n=56)$ \\
\hline \multicolumn{3}{|l|}{ Marital status } \\
\hline Single & $254(93.7)$ & $52(92.9)$ \\
\hline Married & $17(6.3)$ & $4(7.1)$ \\
\hline \multicolumn{3}{|l|}{ Education level } \\
\hline Primary school & $52(19.2)$ & $13(23.2)$ \\
\hline High school & $196(72.32)$ & $39(69.94)$ \\
\hline University Degree & $23(8.48)$ & $4(7.1)$ \\
\hline \multicolumn{3}{|l|}{ Occupation } \\
\hline Self-employed & $183(67.5)$ & $39(69.6)$ \\
\hline Office worker & $88(32.5)$ & $17(30.4)$ \\
\hline \multicolumn{3}{|l|}{ Drugs reported having ever used (local name) } \\
\hline Opium (taryak) & $16(5.9)$ & $4(7.1)$ \\
\hline Heroin & $55(20.4)$ & $10(17.9)$ \\
\hline "Crack" (purer form of heroin) and Methamphetamine (crystal) & $22(8.1)$ & $3(5.4)$ \\
\hline All drugs & $177(65.6)$ & $39(69.6)$ \\
\hline \multicolumn{3}{|l|}{ Types of consumption } \\
\hline Injection & $16(5.9)$ & $7(12.5)$ \\
\hline Inhalational & $7(2.6)$ & $2(3.6)$ \\
\hline Smoking & $25(9.2)$ & $2(3.6)$ \\
\hline All items & $223(82.3)$ & $45(80.4)$ \\
\hline \multicolumn{3}{|l|}{ Duration of drug abuse } \\
\hline 1 - 5 years & $43(15.9)$ & $1(1.8)$ \\
\hline $6-10$ & $105(38.7)$ & $25(44.6)$ \\
\hline $11-15$ & $65(24.0)$ & $13(23.2)$ \\
\hline $16-20$ & $38(14.0)$ & $16(23.2)$ \\
\hline $20<$ & $20(7.4)$ & $4(7.1)$ \\
\hline \multicolumn{3}{|l|}{ Blood transfusion } \\
\hline No & $217(80.7)$ & $46(82.1)$ \\
\hline Yes & $52(19.3)$ & $10(17.9)$ \\
\hline \multicolumn{3}{|l|}{ Past incarceration } \\
\hline No & $106(39.1)$ & $5(8.9)$ \\
\hline Yes & $165(60.9)$ & $51(91.1)$ \\
\hline \multicolumn{3}{|l|}{ History of tattooing } \\
\hline No & $119(45.1)$ & $15(26.8)$ \\
\hline Yes & $145(54.9)$ & $41(73.2)$ \\
\hline \multicolumn{3}{|l|}{ History of surgery } \\
\hline No & $158(58.5)$ & $34(61.8)$ \\
\hline Yes & $112(41.5)$ & $21(38.2)$ \\
\hline \multicolumn{3}{|l|}{ History of liver disease (familial history) } \\
\hline No & $187(87.8)$ & $49(87.5)$ \\
\hline Yes & $26(12.2)$ & $7(12.5)$ \\
\hline \multicolumn{3}{|l|}{ History of high risk sexual behaviors } \\
\hline No & $159(58.67)$ & $39(69.64)$ \\
\hline Yes & $112(41.32)$ & $17(6.27)$ \\
\hline
\end{tabular}




\subsection{Risk Behaviors Associated with $\mathrm{HCV}$}

There was no significant association between these infections with gender and source of sampling $(\mathrm{P}=1.000)$.

The prevalence of HCV was significantly higher between 31 - 40 years old $(\mathrm{P}=0.002)$. The results indicated that longstanding drug abuse ( $>5$ years) was significantly associated with $\mathrm{HCV}$ infection $(\mathrm{P}=0.007)$.

In this study, the history of opioid use was documented; 7.1\% (4 cases) of HCV-positive volunteers patients had used opium, $5.4 \%$ (3 cases) methamphetamine (crystal), 17.9\% (10 cases) heroin, and 69.6\% (39 cases) have had all types of consumption. None had used "crack" (a purer form of heroin).

The demographic characteristics and risk behaviors of detained addicts are described in Tables 1 - 3. The chisquare test revealed that the factors significantly positively associated with HCV infection included age ( $\mathrm{P}=$ $0.002)$, past incarceration $(P \leq 0.001)$, drug injection history $(\mathrm{P}=0.047)$, the duration of drug use $(\mathrm{P}=0.007)$, tattooing $(\mathrm{P}=0.002)$, and heroin use $(\mathrm{P}>0.05)$.

We found no statistical association between HCV and other demographic characteristics, included gender $(\mathrm{P}=$ 1.000), a history of surgery ( $\mathrm{P}=0.647)$, a history of blood transfusion $(\mathrm{P}=0.851)$, educational level $(\mathrm{P}=0.155)$, a history of liver disease $(\mathrm{P}=1)$, marital status (single or married $)(P=0.759)$, and employment status $(P=0.751)$.

\section{Discussion}

Chronic liver diseases are serious health challenge worldwide. HBV or HCV infection is the main cause of liver insufficiency, with various frequency rates in different regions with different varieties of all over the world. Various studies on blood-borne infections have been conducted in Iran among drug users in different cities and different settings, such as IDUs in drug treatment centers, prisons, and in communities. It is well known that designing an effective management approach to control the prevalence of HIV, HCV, and HBV is a great challenge for health authorities. Therefore, information from a variety of populations and risk factors among them would be useful in understanding the correlation between these infections and the correlated factors in the transmission of each of them. Our study was conducted to study HCV and co-infections with HIV and HBV and to assess the related risk factors among drug abuse treatment centers in Khorramabad, Lorestan, Iran. In the current study, $16.23 \%$ of volunteers were positive for HCV. The prevalence of anti-HCV found in this study was high, but lower than that found in most previous studies. The. prevalence of HCV varies geographically, both within and between countries.

In early reports from Tehran by Zali et al. (9), ELISA tests were HCV-positive for $45 \%$ of imprisoned IDUs. In 2001 in the northwestern province of Zanjan, Iran, the HCV prevalence was $47.7 \%$ among 346 drug addict prisoners (13). The HCV prevalence was $60 \%$ among incarcerated IDUs in Mashhad, Iran (15). Kheirandish et al. (16) reported an 80.0\% HCV prevalence among male IDUs in detention in Tehran, Iran. Furthermore, about 38\% of IDU prisoners in the western province of Hamadan, 52\% in Tehran, $64.8 \%$ in the southern cities of Bandar Abbas and Roodan, and $88.9 \%$ in the northern province of Guilan were HCV Ab-positive, whereas the rate in non-IDUs in prison was much lower $(17,18)$. In our investigation, we studied some risk factors related to HCV. The age-specific analysis of the subjects suggested that prevalence of drug abuse was significantly higher between 31 to 40 year olds. The mean age was 31.7 years. Other studies in Iran have shown that young age groups are more prone to using drugs $(19,20)$.

Furthermore, this finding could be due to Iran's young population. In other countries, this age group is more susceptible to drug consumption. Interestingly, in the present study about $98 \%$ of the addicts were male. This could indicate the higher prevalence of high-risk behaviors among men compared to women, demonstrating males' tendency toward addiction and drug injection in Iran. The male gender was reported as an independent predictive factor for $\mathrm{HCV}$ infection in different studies (21, 22). However, some studies have suggested there has been a rising number of female drug users over the past two decades (22). HCV is transmitted through contaminated blood transfusion, surgery, surgical instruments, and dental surgery (23). Some healthcare procedures, i.e., surgical and dental treatments, have recently been indicated as risk factors for acute $\mathrm{HCV}(24)$, but there was no significant difference between a history of surgery and HCV infection in this study. No significant difference was found between the HCV infection rate and a history of blood transfusions. The main risk factor for acquiring HCV infection before the routine anti-HCV screening of blood donors was blood transfusion in Iran; we started a blood donor screening program in all Iranian blood transfusion centers in 1996. Prior researchers have shown that the HCV infection rate has significantly reduced since the blood screening (25). The development of tests for surrogate markers for HCV and the screening of blood donors has reduced the risk of HCV transmission to $0.001 \%$ per unit of transfused blood in developed countries (26). In our study, HC- positive status was significantly associated with intravenous drug use.

IDUs constitute one of the most important groups at risk of being infected with HCV since they share contaminated needles and other equipment used in injection, use shooting galleries, use cocaine, engage in unsafe sexual activities, and share shaving equipment. They not only have the highest prevalence of HCV infection, but also constitute a potential reservoir of HCV in the community (6).

However, there are several studies in Iran showing that injected drug use is one of the main factors associated with the prevalence of HCV infection $(6,7)$. Our study has shown that HCV-positive patients had longstanding drug abuse (addictions); $98.1 \%$ of HCV-positive cases had 
abused drugs for $>6$ years. These findings are concerning two reasons. First, longstanding drug use makes treatment very difficult. Second, long-term opiate use can leads to drug injection as result, which is a sufficient amount of time to be afflicted with different infections transmitted by injection (27). Injecting and needle sharing are believed to be the major risk factors for HIV and HCV infections among IDUs. In addition, we found that individuals with a shorter duration of drug abuse were less likely to be HCV seropositive.

The majority of these volunteers had a prison history, showing that cases with a history of imprisonment are much more likely to inject drugs than IDUs without a history of imprisonment.

Our study corroborates the potential role of incarceration in propagating of HCV. As described in other studies, incarceration can lead to increased sharing of injection equipment due to the scarcity of clean needles and syringes (28). is consistent with multiple studies around the world that also find incarceration associated with HCV infection and with the injection-related practices that lead to HCV infection $(15,29)$. In addition, it is possible for non-injection drug users to be at elevated risk for HCV due to incarceration (30). As matter of fact, the incarceration of non-injecting opioid users can precipitate their change to injection, as smoking opium in jails is difficult to conceal. Thus, incarceration may accelerate HCV transmission among IDUs and among previously non-injecting drug users. Nearly $40 \%$ of Iranian prisoners were IDUs, and the prevalence of HCV infection among this population has been reported to be between 38 and $90 \%(15,17)$. In high-risk populations in comparison to the general population, tattooing may increase risk status (5). The association between HCV infection and a history of being tattooed inside prison has been reported in other countries. We also found that a history of tattooing that was an independent risk factor for HCV infection (1214). In the United States, Samuel et al. (12) reported that the receipt of a tattoo inside prison or jail was associated with both HBV and HCV. In Australia, it was also found that being tattooed was an independent risk factor for being HCV positive among a group of prisoners (31). The risk of tattooing for the transmission of HCV infection has also been reported in earlier studies among IDUs in Iran (9). In a study of prisoners in Zanjan, Iran, Khani et al. (13) reported that tattooing was associated with HCV positivity among prisoners. Another study has shown that tattoos might have a higher risk of HCV infection when given in prison (32).

In our study, most subjects had only a primary/secondary school degree, which can be result of dropping out of high school (73.2\%)and 7.1\% had university degree. A low educational level and/or low socioeconomic status has also been associated with the prevalence of a number of infectious diseases, but we found no statistical association between HCV and educational level.

In conclusion, these studies showed that risk character- istics, including injected drug use, homosexual sexual practice, tattooing, and the length of incarceration, are among potential correlates of HCV infection among drug addicts in Khorrambad, Lorestan, Iran. Continued education of public and healthcare professionals will play an important part in controlling this problem since injections in the community are reported as a risk factor for the acquisition of HBV and HCV.

\section{Acknowledgments}

Special thanks to Lorestan University of Medical Sciences for their financial support of this study. The authors thank the head and staff of the Razi herbal medicines research center of Lorestan University of Medical Sciences.

\section{Footnote}

Authors' Contribution:Study concept and design: Mohammadreza Gholami, Hossein Norouzian, and Gholamreza Goudarzi; analysis and interpretation of data: Hossein Norouzian and Mohammadreza Gholami; drafting of the manuscript: Mohammadreza Gholami; critical revision of the manuscript for important intellectual content: Hossein Norouzian, Azam Rezvani, Gholamreza Goudarzi, Pegah Shakib, and Hamze Ghobadian Diali; statistical analysis: Mohammadreza Gholami and Hossein Norouzian.

\section{References}

1. Wild CP, Hall AJ. Primary prevention of hepatocellular carcinoma in developing countries. Mutat Res. 2000;462(2-3):381-93. [PubMed:10767647]

2. Burattini M, Massad E, Rozman M, Azevedo R, Carvalho H. Correlation between HIV and HCV in Brazilian prisoners: evidence for parenteral transmission inside prison. Rev Saude Publica. 2000;34(5):431-6. [PubMed: 11105105]

3. Pittock SJ, Lucchinetti CF, Parisi JE, Benarroch EE, Mokri B, Stephan CL, et al. Amphiphysin autoimmunity: paraneoplastic accompaniments. Ann Neurol. 2005;58(1):96-107. doi: 10.1002/ ana.20529. [PubMed: 15984030 ]

4. Zeldis JB, Jain S, Kuramoto IK, Richards C, Sazama K, Samuels S, et al. Seroepidemiology of viral infections among intravenous drug users in northern California. West J Med. 1992;156(1):30-5. [PubMed:1310362]

5. Mohammad Alizadeh AH, Alavian SM, Jafari K, Yazdi N. Prevalence of hepatitis $\mathrm{C}$ virus infection and its related risk factors in drug abuser prisoners in Hamedan-Iran. World J Gastroenterol. 2005;11(26):4085-9. [PubMed: 15996035]

6. Alavian SM, Gholami B, Masarrat S. Hepatitis C risk factors in Iranian volunteer blood donors: a case-control study. J Gastroenterol Hepatol. 2002;17(10):1092-7. [PubMed:12201870]

7. Hajiani E, Hashemi J, Masjedizadeh R, Shayesteh AA, Idani E, Rajabi T. Seroepidemiology of hepatitis $C$ and its risk factors in Khuzestan Province, south-west of Iran: a case-control study. World J Gastroenterol. 2006;12(30):4884-7. [PubMed:16937474]

8. Taylor A, Goldberg D, Hutchinson S, Cameron S, Fox R. High risk injecting behaviour among injectors from Glasgow: cross sectional community wide surveys 1990-1999. J Epidemiol Community Health. 2001;55(10):766-7. [PubMed: 11553663]

9. Zali MR, Aghazadeh R, Nowroozi A, Amir-Rasouly H. Anti-HCV antibody among Iranian IV drug users: is it a serious problem. Arch Iran Med. 2001;4(3):115-9.

10. Shafer KP, Hahn JA, Lum PJ, Ochoa K, Graves A, Moss A. Prevalence and correlates of HIV infection among young injection drug us- 
ers in San Francisco. J Acquir Immune Defic Syndr. 2002;31(4):42231. [PubMed:12447014]

11. Alavian SM, Adibi P, Zali MR. Hepatitis C virus in Iran: Epidemiology of an emerging infection. Arch Iranian Med. 2005;8(2):84-90.

12. Samuel MC, Doherty PM, Bulterys M, Jenison SA. Association between heroin use, needle sharing and tattoos received in prison with hepatitis B and C positivity among street-recruited injecting drug users in New Mexico, USA. Epidemiol Infect. 2001;127(3):475-84. [PubMed: 11811881]

13. Khani M, Vakili MM. Prevalence and risk factors of HIV, hepatitis $B$ virus and hepatitis $C$ virus infections in drug addicts among Zanjan prisoners. Arch Iranian Med. 2003;6(1):1-4.

14. Babudieri S, Longo B, Sarmati L, Starnini G, Dori L, Suligoi B, et al. Correlates of HIV, HBV, and HCV infections in a prison inmate population: results from a multicentre study in Italy.J Med Virol. 2005;76(3):311-7. doi:10.1002/jmv.20375. [PubMed: 15902712]

15. Rahbar A, Rooholamini S, Khoshnood K. Prevalence of HIV infection and other blood-borne infections in incarcerated and nonincarcerated injection drug users (IDUs) in Mashhad, Iran. Int J Drug Policy. 2004;15(2):151-5. doi:10.1016/j.drugpo.2003.07.001.

16. Kheirandish P, SeyedAlinaghi S, Jahani M, Shirzad H, Seyed Ahmadian M, Majidi A, et al. Prevalence and correlates of hepatitis C infection among male injection drug users in detention, Tehran, Iran. J Urban Health. 2009;86(6):902-8. doi: 10.1007/s11524-0099393-0. [PubMed:19844670]

17. Mohtasham Amiri Z, Rezvani M, Jafari Shakib R, Jafari Shakib A. Prevalence of hepatitis $\mathrm{C}$ virus infection and risk factors of drug using prisoners in Guilan province. East Mediterr Health J. 2007;13(2):250-6. [PubMed:17684845]

18. Davoodian P, Dadvand H, Mahoori K, Amoozandeh A, Salavati A. Prevalence of selected sexually and blood-borne infections in Injecting drug abuser inmates of bandar abbas and roodan correction facilities, Iran, 2002. Braz J Infect Dis. 2009;13(5):356-8. doi: 10.1590/S1413-86702009000500008. [PubMed:20428635]

19. Alavi SM, Etemadi A. HIV/HBV, HIV/HCV and HIV/HTLV-1 co infection among injecting drug user patients hospitalized at the infectious disease ward of a training hospital in Iran. Pakistan Journal of Medical Sciences. 2007;23(4):510.

20. Evans JL, Hahn JA, Page-Shafer K, Lum PJ, Stein ES, Davidson PJ, et al. Gender differences in sexual and injection risk behavio among active young injection drug users in San Francisco (the UFO Study).J Urban Health. 2003;80(1):137-46. doi:10.1093/jurban/ jtg137. [PubMed: 12612103]

21. Alavian SM, Kabir A, Ahmadi AB, Lankarani KB, Shahbabaie MA, Ahmadzad-Asl M. Hepatitis C infection in hemodialysis patients in Iran: a systematic review. Hemodial Int. 2010;14(3):253-62. doi: 10.1111/j.1542-4758.2010.00437.x. [PubMed:20491973]

22. Kafi-abad SA, Rezvan H, Abolghasemi H, Talebian A. Prevalence and trends of human immunodeficiency virus, hepatitis B virus, and hepatitis $C$ virus among blood donors in Iran, 2004 through 2007. Transfusion. 2009;49(10):2214-20. doi:10.1111/j.15372995.2009.02245.x. [PubMed:19527477]

23. Van Staa A, Hardon A. Injection practices in the developing world. Geneva; World Health Organization. 1996.

24. Mele A, Tosti ME, Marzolini A, Moiraghi A, Ragni P, Gallo G, et al. Prevention of hepatitis C in Italy: lessons from surveillance of type-specific acute viral hepatitis. SEIEVA collaborating Group. Viral Hepat. 2000;7(1):30-5. [PubMed: 10718940]

25. Akbari A, Imanieh MH, Karimi M, Tabatabaee HR. Hepatitis C virus antibody positive cases in multitransfused thalassemic patients in South of Iran. Hepat Mon. 2007;7(2):63-6.

26. Alavian SM, Fallahian F, Lankarani KB. Comparison of seroepidemiology and transmission modes of viral hepatitis C in Iran and Pakistan. Hepat Mon. 2008;8(1):51-9.

27. Aceijas C, Friedman SR, Cooper HL, Wiessing L, Stimson GV, Hickman M. Estimates of injecting drug users at the national and local level in developing and transitional countries, and gender and age distribution. Sex Transm Infect. 2006;82 Suppl 3:iii10-7. doi:10.1136/sti.2005.019471. [PubMed:16735287]

28. Razzaghi EM, Movaghar AR, Green TC, Khoshnood K. Profiles of risk: a qualitative study of injecting drug users in Tehran, Iran Harm Reduct J. 2006;3:12. doi: 10.1186/1477-7517-3-12. [PubMed 16545137]

29. Quaglio G, Lugoboni F, Pajusco B, Sarti M, Talamini G, Lechi A, e al. Factors associated with hepatitis $\mathrm{C}$ virus infection in injection and noninjection drug users in Italy. Clin Infect Dis. 2003;37(1):3340. doi: 10.1086/375566. [PubMed:12830406]

30. Day C, Nassirimanesh B, Shakeshaft A, Dolan K. Patterns of drug use among a sample of drug users and injecting drug users attending a General Practice in Iran. Harm Reduct J. 2006;3:2. doi: 10.1186/1477-7517-3-2. [PubMed: 16433914]

31. Hellard ME, Hocking JS, Crofts N. The prevalence and the risk behaviours associated with the transmission of hepatitis $C$ virus in Australian correctional facilities. Epidemiol Infect. 2004;132(3):409-15. [PubMed:15188710]

32. Zamani S, Ichikawa S, Nassirimanesh B, Vazirian M, Ichikawa K, Gouya MM, et al. Prevalence and correlates of hepatitis C virus infection among injecting drug users in Tehran. Int J Drug Policy. 2007;18(5):359-63. doi: 10.1016/j.drugpo.2007.02.007. [PubMed 17854723] 